\title{
Performance and Environmental Test Results of the High Voltage Hall Accelerator Engineering Development Unit
}

\author{
Hani Kamhawi ${ }^{*}$, Thomas Haag ${ }^{\dagger}$, Wensheng Huang ${ }^{\ddagger}$, Rohit Shastry ${ }^{\S}$, Luis Pinero**, Todd Peterson ${ }^{\dagger}$ \\ National Aeronautics and Space Administration Glenn Research Center, Cleveland, Ohio, 44135 \\ and \\ Alex Mathers \\ Aerojet General Corporation, Redmond, WA 98073
}

\begin{abstract}
NASA Science Mission Directorate's In-Space Propulsion Technology Program is sponsoring the development of a $3.5 \mathrm{~kW}$-class engineering development unit Hall thruster for implementation in NASA science and exploration missions. NASA Glenn and Aerojet are developing a high fidelity high voltage Hall accelerator that can achieve specific impulse magnitudes greater than 2,700 seconds and xenon throughput capability in excess of 300 kilograms. Performance, plume mappings, thermal characterization, and vibration tests of the high voltage Hall accelerator engineering development unit have been performed. Performance test results indicated that at $3.9 \mathrm{~kW}$ the thruster achieved a total thrust efficiency and specific impulse of $58 \%$, and $2,700 \mathrm{sec}$, respectively. Thermal characterization tests indicated that the thruster component temperatures were within the prescribed material maximum operating temperature limits during full power thruster operation. Finally, thruster vibration tests indicated that the thruster survived the 3-axes qualification full-level random vibration test series. Pre and post-vibration test performance mappings indicated almost identical thruster performance. Finally, an update on the development progress of a power processing unit and a xenon feed system is provided.
\end{abstract}

\section{Introduction}

$\mathrm{E}$ ectric propulsion (EP) systems can enable and enhance NASA's ability to perform scientific space exploration. NASA Science Mission Directorate (SMD) planetary science missions to small bodies include fly-by, rendezvous, and sample return from a diverse set of targets. For example, NASA missions have successfully employed EP systems in Deep Space 1 (DS1) and Dawn missions. ${ }^{2,3}$ To augment its capability to perform these and other solar system exploration missions, NASA continues to develop advanced EP technologies. ${ }^{4}$ Recent small body mission studies indicate that the majority of these small body missions are enabled by the use of EP and nearly all of the small body missions of interest are enhanced with EP. ${ }^{5}$

Electric propulsion systems performance can significantly reduce launch vehicle requirements, costs, and spacecraft mass because of its high specific impulse capability when compared to chemical propulsion. A recent study was performed to evaluate potential cost savings that can be realized by use of EP when compared to chemical propulsion for NASA Discovery class missions. ${ }^{6}$ A Hall thruster system can become cost competitive with alternative chemical propulsion systems if the Hall and chemical thrusters are held to the same fault tolerance. The Hall thruster system option will not only enable a wide range of Discovery class missions but will enable science return far greater than the chemical alternatives. Table 1 summarizes the major study findings. The study also found

\footnotetext{
* Research Engineer, Propulsion and Propellants Branch, hani.kamhawi-1@nasa.gov, AIAA Associate Fellow.

${ }^{\dagger}$ Propulsion Engineer, Space Propulsion Branch. Thomas.w.haag@ nasa.gov, AIAA member.

${ }^{*}$ Research Engineer, Propulsion and Propellants Branch, wensheng.huang@ nasa.gov, AIAA Member.

${ }^{\S}$ Research Engineer, Propulsion and Propellants Branch, rohit.shastry@ nasa.gov, AIAA Member.

*** Research Engineer, Propulsion and Propellants Branch, luis.r.pinero@ nasa.gov, AIAA Associate Fellow

${ }^{\dagger}$ Project Manager, Space Science Project, todd.peterson@nasa.gov. AIAA Member.

\# Program Manager, EP Systems, Aerojet Redmond Operations, alex.mathers@aerojet.com, AIAA Member.
} 
that substantial cost savings can be realized when using a Hall versus a gridded-ion EP system as is presented in Table 2 below.

Table. 1 Comparison of chemical and electric propulsion system (NEXT ion and Hall) delta costs for NASA Discovery class missions.

\begin{tabular}{|c|c|c|}
\hline Thruster & Config. & Cost $\Delta \$ \mathrm{M}$ \\
\hline NEXT $1^{\text {st }}$ User & $1+1$ & 26.5 \\
\hline Next $\mathrm{n}^{\text {th }}$ User & $1+1$ & 7.0 \\
\hline Hall $1^{\text {st }}$ User & $1+1$ & 6.5 \\
\hline Hall $\mathrm{n}^{\text {th }}$ User & $1+1$ & 0.5 \\
\hline $\begin{array}{c}\text { Chemical } \\
\text { Bipropellant }\end{array}$ & $1+0$ & Baseline \\
\hline
\end{tabular}

Table. 2 Comparison of gridded ion (NEXT) and Hall propulsion system delta costs for NASA Discovery class missions.

\begin{tabular}{|c|c|c|c|}
\hline & Thruster & Config. & Cost $\Delta \$ \mathrm{M}$ \\
\hline \multirow{4}{*}{$\begin{array}{c}\text { First } \\
\text { User }\end{array}$} & \multirow{3}{*}{ NEXT } & $1+0$ & -8.1 \\
\cline { 3 - 4 } & & $1+1$ & Baseline \\
\cline { 3 - 4 } & \multirow{3}{*}{ Hall } & $2+1$ & 6.5 \\
\cline { 3 - 4 } & & $1+0$ & -25.2 \\
\cline { 3 - 4 } & & $1+1$ & -20.0 \\
\hline Nth & NEXT & $1+1$ & -15.0 \\
\cline { 3 - 4 } User & Hall & $1+1$ & -19.6 \\
\hline
\end{tabular}

NASA SMD's In-Space Propulsion Technology Project (ISPT) funds new EP system development for future NASA science missions. ${ }^{7}$ The two primary EP elements of this project are the development of NASA's Evolutionary Xenon Thruster (NEXT) ion thruster propulsion system ${ }^{8}$ for NASA Flagship, New Frontiers and Discovery class missions and the development of a long-life High Voltage Hall Accelerator (HiVHAc) ${ }^{9}$ as a lower cost EP option for NASA Discovery class science missions.

In 2004, mission studies found that a Hall thruster system with performance characteristics similar to the HiVHAc thruster resulted in substantial cost and performance benefits when compared to the NASA Solar Electric Propulsion Technology Application Readiness (NSTAR) and NEXT ion engine systems for certain NASA Discovery class science missions. ${ }^{10,11,12,13}$

Additional mission studies performed in 2009 evaluated the performance of the HiVHAc $3.5 \mathrm{~kW}$ thruster and a state-of-the-art (SOA) $4.5 \mathrm{~kW}$ flight Hall thruster. ${ }^{14,15}$ Four NASA Discovery class design reference missions (DRMs) were evaluated:

- Vesta-Ceres rendezvous mission (i.e., Dawn Mission) which has both time constraints and an very high post launch $\Delta \mathrm{V}$, requiring both moderate thrustto-power and a higher specific impulse than a conventional Hall thruster;

- Koppf comet rendezvous mission has few constraints and does not thrust in gravity wells (this favors a high specific impulse throttle table);

- Near-Earth Asteroid Return Earth Return (NEARER) mission; and

- Nereus sample return (NSR) mission which is a relatively low $\Delta \mathrm{V}$ mission with time constraints, favorable for a higher thrust-to-power thruster.

Results from the mission studies indicated that the HiVHAc thruster was able to meet and exceed the needs of all the evaluated missions. Figure 1 presents the mission analysis results for the Dawn mission using the HiVHAc

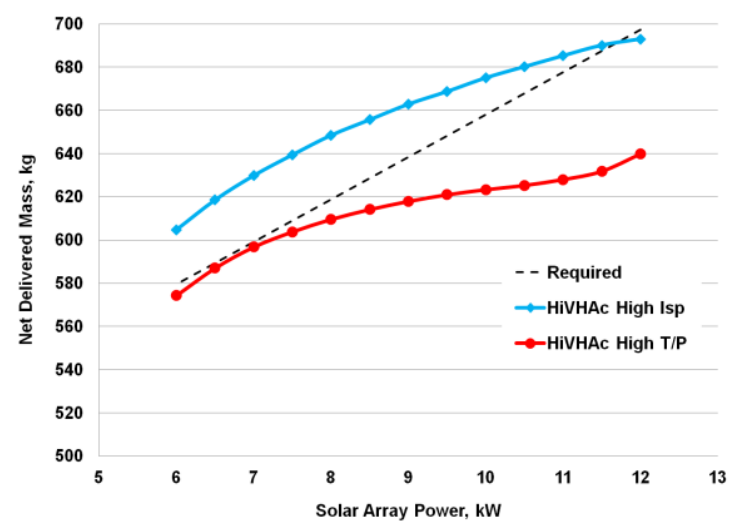

Figure 1. HiVHAc thruster performance for the Dawn mission. throttle table.

This paper is organized as follows: Section II provides an overview of the projected HiVHAc system. Section III provides an overview of the engineering development unit 1 (EDU 1) history and summarizes the reasons for manufacturing of a second unit designated EDU 2. Section III also presents EDU 2 performance (pre and post vibration test), thermal characterization, and random vibration test results. Section IV provides an update on the HiVHAc power processing unit development options. Section V provides an update on the HiVHAc xenon feed system development. Section VI discusses EDU 2 thruster test roadmap. Section VII summarizes the content of this paper. 


\section{High Voltage Hall Accelerator System}

The major elements of the high-specific impulse long-life Hall propulsion system that is being developed and matured include EDU2, power processing unit (PPU), and xenon feed system (XFS) as is shown in Figure 2. The EDU 2 development and testing are being performed by NASA GRC and Aerojet and will be further detailed in this paper. For the PPU development, the HiVHAc project has been leveraging and evaluating PPU developments that have been sponsored by industry and NASA's SBIR program but that can apply directly to a Hall propulsion system. The most mature PPU is a brassboard unit developed by Colorado Power Electronics (CPE). For XFS development, the HiVHAc project and Air Force Research Laboratory (AFRL) are furthering the development of an ISPT-funded advanced Xenon Flow Control Module (XFCM) by VACCO Industries.

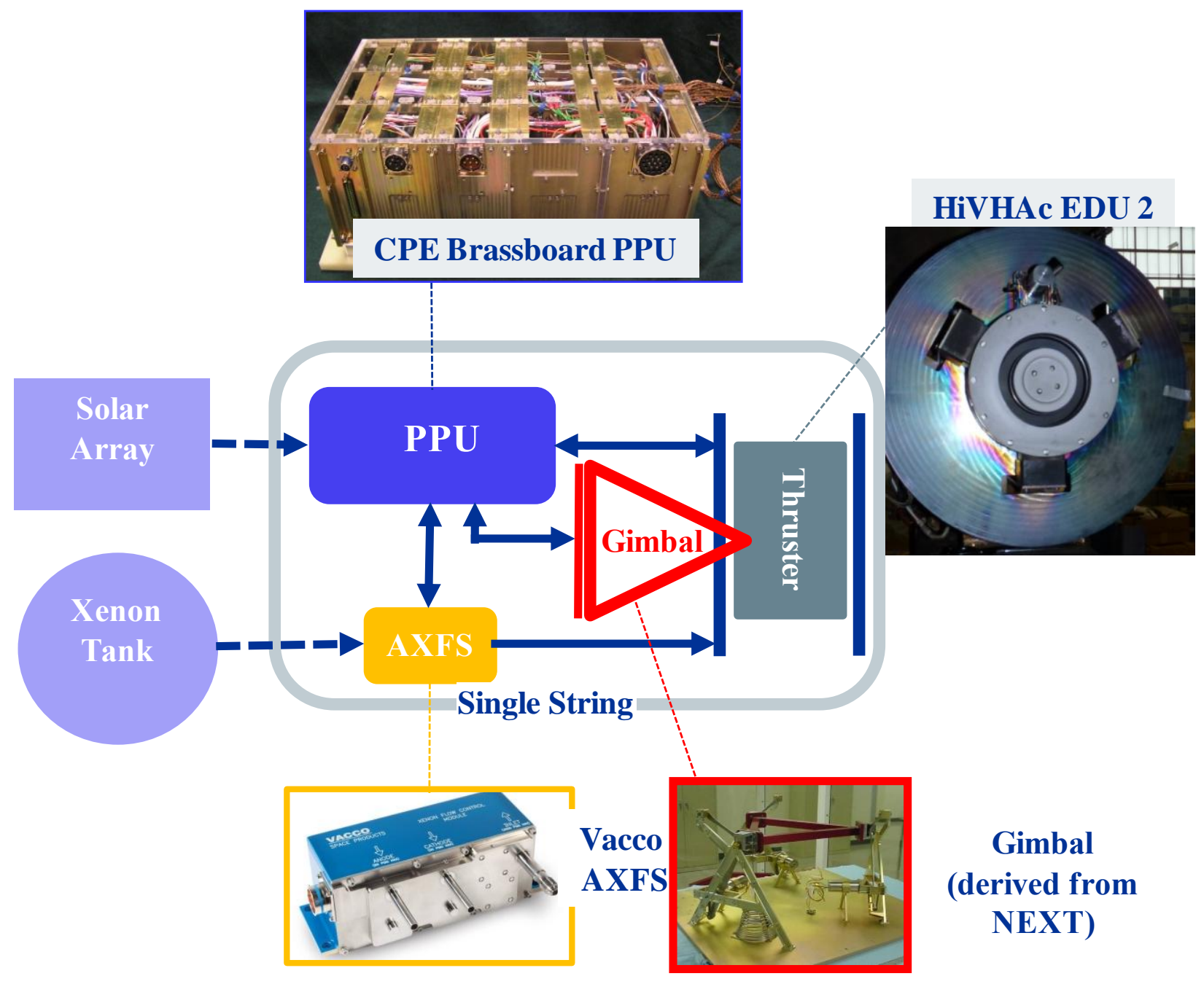

Figure 2. Layout of the HiVHAc system showing its major sub-systems. 


\section{High Voltage Hall Accelerator Thruster Engineering Development Units Test Results}

To demonstrate the HiVHAc project performance, throttleability, and lifetime goals, the NASA-77M and the NASA-103M.XL laboratory thrusters were built and tested. ${ }^{13}$ The NASA-103M.XL (eXtended Life) incorporated an innovation that performs discharge channel replacement during thruster operation. ${ }^{16,17}$ Wear testing of the NASA103M.XL thruster was performed to demonstrate the life-extending channel replacement innovation. The wear test demonstrated $>5,000$ hours of operation at a discharge voltage of $700 \mathrm{~V}$, which represents a xenon throughput of $>100 \mathrm{~kg}^{16,18}$

After the successful demonstration and validation of the life-extending channel replacement innovation with the NASA-103M.XL laboratory thruster, NASA GRC teamed with Aerojet to design, manufacture, and test a high fidelity EDU thruster.

\section{A. High Voltage Hall Accelerator Thruster Engineering Development Unit 1:}

The goal of EDU 1 design and manufacturing effort was to demonstrate a high fidelity HiVHAc thruster. ${ }^{19}$ The EDU 1 thruster was designed to be throttleable with performance levels that meet or exceed levels achieved by the NASA-103M.XL laboratory thruster. The EDU 1 thruster design incorporated the life-extending channel replacement mechanism. The EDU 1 was designed to survive structural and thermal environments for representative spacecraft and missions. To meet EDU 1 requirements, an extensive analysis, design, manufacturing, and testing plan was devised and reported earlier. ${ }^{20}$ The design leveraged all the experience, knowledge, and lessons learned during the development of the NASA-77M and NASA-103M.XL thrusters in addition to incorporating Aerojet's experience in manufacturing the flight qualified BPT-4000 Hall thruster propulsion system. The NEXT environmental requirements (representative of NASA New Frontiers class mission) were used in the HiVHAc EDU 1 thruster design. ${ }^{21}$ For the thermal requirements definition, the hot environment was based on a Venus flyby mission, and the cold environment was based on a distance of 4 Astronomical Units (AU) from the Sun. ${ }^{14}$

Extensive functional and performance tests of EDU 1 were performed. Although the thruster performance levels exceeded the design goals, ${ }^{22}$ the tests revealed several areas that needed further refinement and design modifications and they are: the magnetic circuit, thermal management, discharge channel replacement mechanism, and high voltage insulator designs.

Thermal characterization tests of EDU 1 indicated that the inner electromagnet temperature was exceeding the maximum wire insulating material operating temperature. In addition, the anode isolator piece (part between the high voltage anode assembly and the low voltage anode mount) had fractured after operating the thruster at $2.5 \mathrm{~kW}$ due to thermal stresses caused by mismatch in thermal expansion coefficients between the anode assembly, anode isolator, and anode mount.

Thruster testing revealed that the channel replacement mechanisms for the inner and outer boron nitride discharge channels were seizing and were not operating as designed. The seizing was partially due to the elevated temperatures that were achieved during full power thruster operation.

Finally, thruster testing also revealed that high voltage breakdowns were occurring within the thruster. These high voltage breakdowns were occurring in locations where there was direct line of sight between high voltage and low voltage components. The high voltage breakdowns occurred mainly between the power and propellant feedlines and the thruster body.

The magnetic circuit, thermal, and high voltage issues were addressed through redesign of certain thruster components. The magnetic circuit design changes resulted in a $10 \%$ higher peak radial magnetic field than initially measured but still lower than the design value. Significantly lower peak inner electromagnet operating temperatures were attained through redesign of the anode isolator and anode mount components. High voltage breakdowns were completely mitigated by eliminating all direct line of sight between the high and low voltage components. Finally, several design modification were implemented to the discharge channel replacement mechanism. These design modifications helped eliminate most of the causes for mechanism seizure. However, further testing of the thruster, indicated that consistent and reliable mechanism operation would require additional redesign of several components of the discharge channel replacement mechanism. As such, NASA GRC explored other mechanism options to perform the function of discharge channel replacement. 


\section{B. High Voltage Hall Accelerator Engineering Development Unit 2}

The design changes that were implemented in EDU 1 helped overcome many of the issues that were found during thruster functional and performance testing. However, the inner electromagnet was still operating at temperatures higher than required and reliable discharge channel replacement mechanism operation remained as unresolved issues. To overcome both challenges, NASA GRC proposed the implementation of a new mechanism to perform the discharge channel replacement function. Compared to the original mechanism, the new mechanism was simpler to implement, and provided additional space for the inner electromagnet. This additional space allowed for a reduced peak operating temperature of the inner electromagnet. Key new features in the new mechanism are:

- The new mechanism design is much simpler than the original mechanism design. The mass and number of components in the new mechanism is less than half that of the original mechanism;

- The new mechanism operation and actuation is less sensitive to the thruster internal thermal environment; and

- The new mechanism occupies much less space than the original mechanism, which results in enhanced radiation losses and the creation of more space for the inclusion of higher gauge wire in the inner electromagnet.

In addition, EDU 2 incorporated new design features that include:

- A more efficient magnetic circuit that preserved EDU 1 magnetic field topology while operating at lower electromagnet currents;

- An anode isolator and anode mount design that greatly enhanced heat conduction from the anode assembly;

- An electromagnet design that operates at lower temperatures; and

- A boron nitride discharge channel configuration that is structurally more robust than the original design.

\section{B.1 Performance Tests}

Performance Acceptance Testing (PAT) of EDU 2 was performed in vacuum facility 12 (VF12) at NASA GRC. Vacuum facility 12 is a 3-m diameter, 9-m long cylindrical cryopumped facility with a pumping speed of approximately 1,000,000 L/sec (air). Recent tests of VF12 indicate a base pressure of $8.9 \times 10^{-8}$ torr. A base pressure of approximately $1 \times 10^{-5}$ torr was attained at a xenon flow rate of 65 sccm. Vacuum facility 12 walls are lined with $1.3 \mathrm{~cm}$ thick graphite paneling to reduce the back-sputtered material flux to the thruster and test support hardware. Figure 3 shows a photograph of EDU 2 mounted inside VF12 on the inverted pendulum thrust stand. ${ }^{23}$ Performance acceptance testing of EDU 2 was performed in December of 2011. The tested EDU 2 thruster did not include the discharge channel replacement mechanism because components were not yet available. Also, a laboratory hollow cathode assembly was utilized during the December test. During the PAT, EDU 2 was operated at power levels between 0.3 and $3.9 \mathrm{~kW}$. The PAT performance results will not be reported in this paper since subsequent performance evaluation in April of 2012 was performed on an EDU 2 thruster configuration that included the discharge channel replacement mechanism and a flight cathode assembly.

Figure 4 shows a photograph of the HiVHAc thruster while operating at 3.9 $\mathrm{kW}$ in VF12. During thruster operation the cathode was operated at a fixed flow rate of approximately $0.45 \mathrm{mg} / \mathrm{sec}$ and a 1 A keeper current was used during all test conditions reported hereafter. Figures 5 and 6 present the discharge efficiency and discharge specific impulse profiles for EDU 2 thruster, respectively. Results in Figure 5 indicate that peak discharge efficiencies of $65 \%$ and $63 \%$ were achieved when EDU 2 was operating at 3.9 $\mathrm{kW}$ at discharge voltages of 600 and $650 \mathrm{~V}$, respectively. Figure 6 indicates that a peak discharge specific impulse of 2,970 sec was achieved when operating the thruster at $3.9 \mathrm{~kW}$ at a discharge voltage of $650 \mathrm{~V}$. Figures 7 and 8 present the total efficiency and total specific impulse profiles for EDU 2,

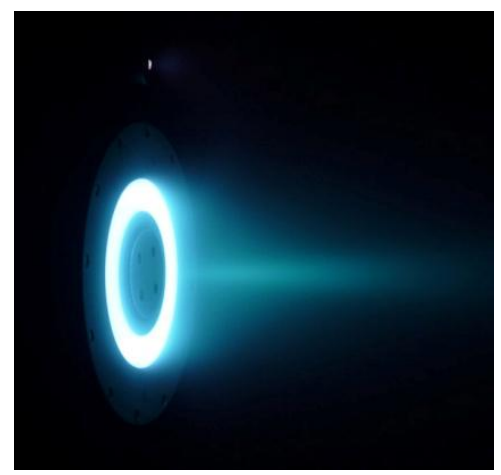

Figure 4. Photograph of EDU 2 while operating in VF12. 
respectively. Figure 7, indicates that peak total thruster efficiencies of $60 \%$ and $58 \%$ were achieved at $3.9 \mathrm{~kW}$ for discharge voltages of 600 and $650 \mathrm{~V}$, respectively. Figure 8, indicates that EDU 2 demonstrated a peak total specific impulse of approximately $2,700 \mathrm{sec}$ at $3.9 \mathrm{~kW}$ at a discharge voltage of $650 \mathrm{~V}$.

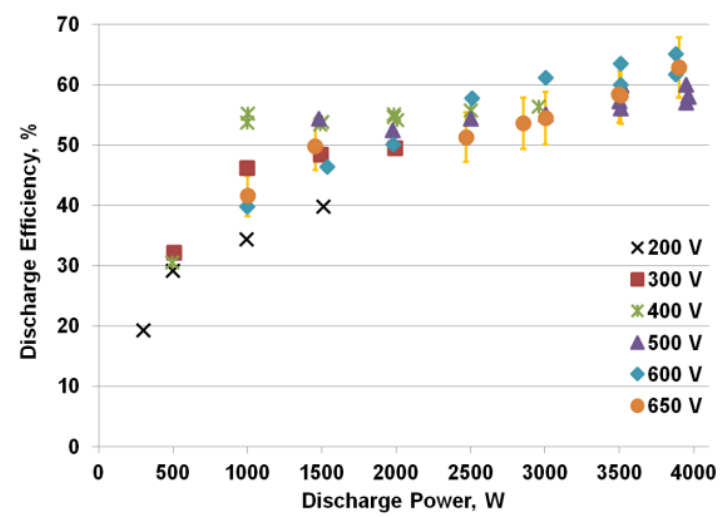

Figure 5. Pre-vibration test EDU 2 discharge efficiency vs. discharge power for discharge voltages between 200 and $650 \mathrm{~V}$.

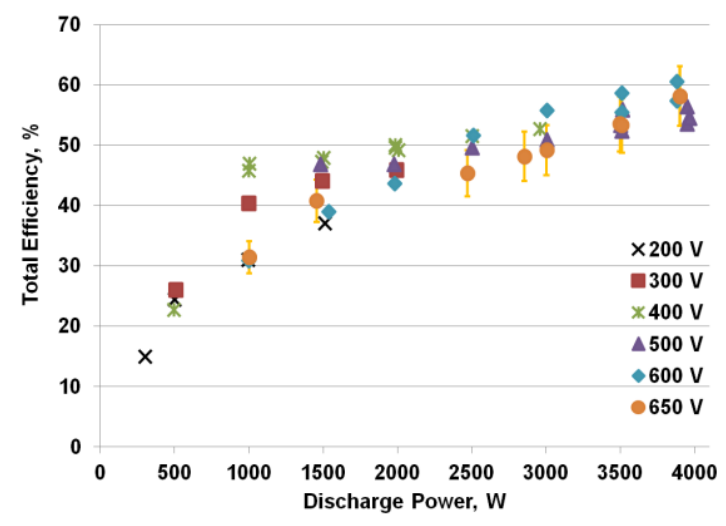

Figure 7. Pre-vibration test EDU 2 total efficiency vs. discharge power for discharge voltages between 200 and $650 \mathrm{~V}$.

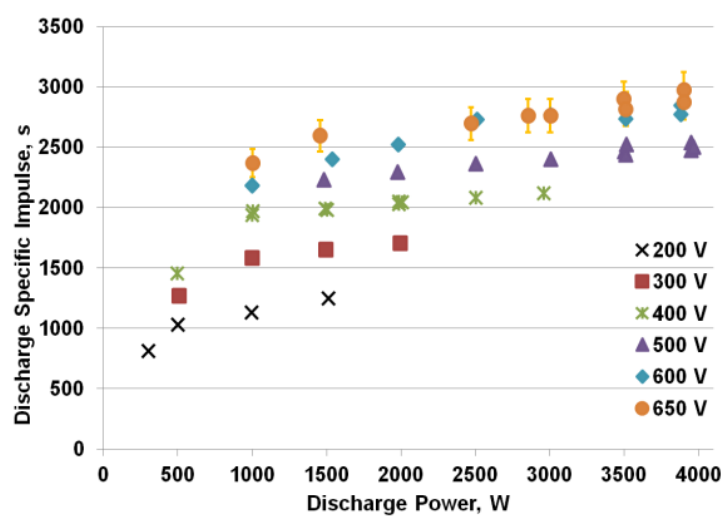

Figure 6. Pre-vibration test EDU 2 discharge specific impulse vs. discharge power for discharge voltages between 200 and $650 \mathrm{~V}$.

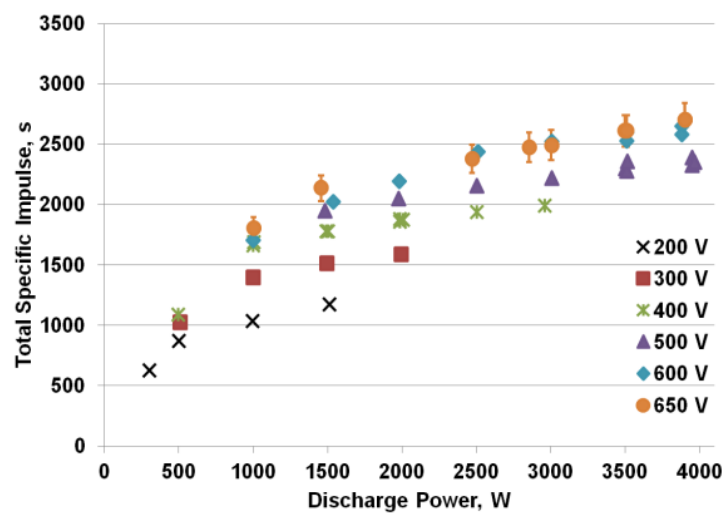

Figure 8. Pre-vibration test EDU 2 discharge specific impulse vs. discharge power for discharge voltages between 200 and $650 \mathrm{~V}$.

Vibration testing of EDU 2 was performed at Aerojet during the week of May 7, 2012. After completion of the vibration test (test details are in a later section), the thruster was shipped back to NASA GRC and post-vibration performance evaluation was performed.

Post-vibration performance evaluation was again performed at power levels between 0.3 and $3.9 \mathrm{~kW}$. Figures 9 and 10 present EDU 2 discharge efficiency and discharge specific impulse profiles, respectively. Results in Figure 9 indicate that peak discharge efficiency of $63 \%$ was achieved when EDU 2 was operating at $3.9 \mathrm{~kW}$ at both discharge voltages of 600 and $650 \mathrm{~V}$. Figure 10 indicates that a peak discharge specific impulse of 2,970 sec was achieved when operating the thruster at $3.9 \mathrm{~kW}$ at a discharge voltage of $650 \mathrm{~V}$. Figures 11 and 12 present EDU 2 total efficiency and total specific impulse profiles, respectively. Figure 11, indicates that peak total thruster efficiency of $58 \%$ were achieved at $3.9 \mathrm{~kW}$ for both discharge voltages of 600 and $650 \mathrm{~V}$. Figure 12, indicates that EDU 2 demonstrated a peak total specific impulse of approximately $2,700 \mathrm{sec}$ at $3.9 \mathrm{~kW}$ at a discharge voltage of $650 \mathrm{~V}$.

Figures 13 and 14 present a comparison between EDU 2 pre- and post-vibration test total thrust and specific impulse results at selected thruster operating conditions. Results show that EDU 2 performance pre and postvibration test is almost identical and is within the accuracy of the reported values. The mostly identical thruster performance is not surprising since EDU 2 inspection after the vibration test indicated that no obvious change to the thruster assembly occurred as a result of being subject to a full-level qualification random vibration test. 


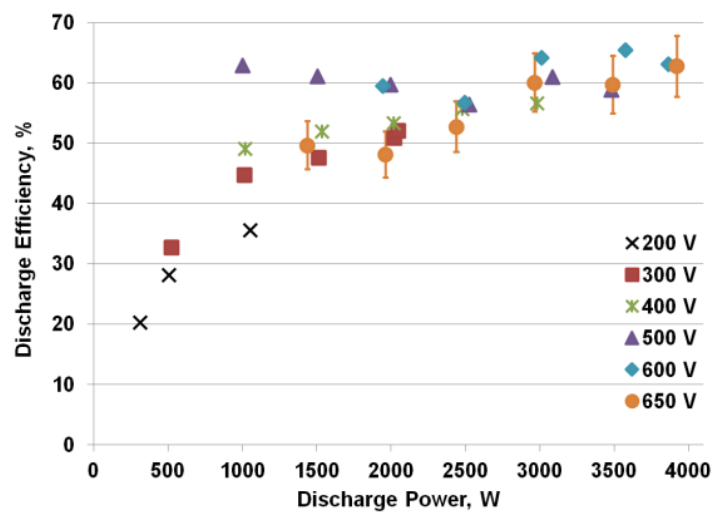

Figure 9. Post-vibration test EDU 2 discharge efficiency vs. discharge power for discharge voltages between 200 and $650 \mathrm{~V}$.

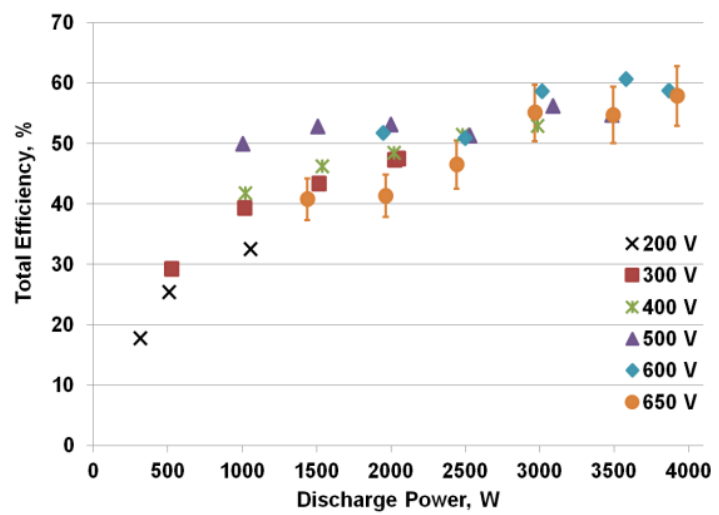

Figure 11. Post-vibration test EDU 2 total efficiency vs. discharge power for discharge voltages between 200 and $650 \mathrm{~V}$.

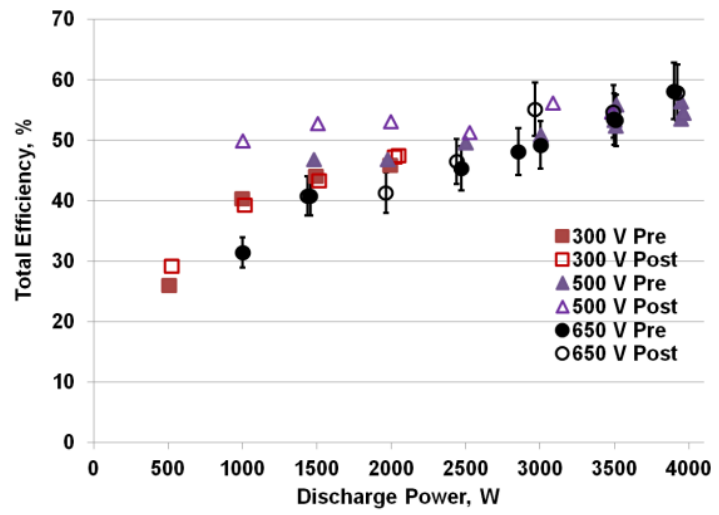

Figure 13. EDU 2 pre- and post-vibration test total efficiency vs. discharge power for selected discharge voltages.

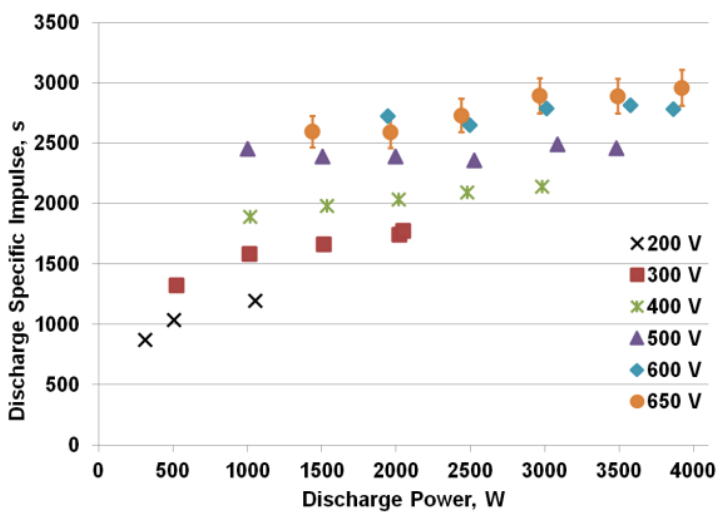

Figure 10. Post-vibration test EDU 2 discharge specific impulse vs. discharge power for discharge voltages between 200 and $650 \mathrm{~V}$.

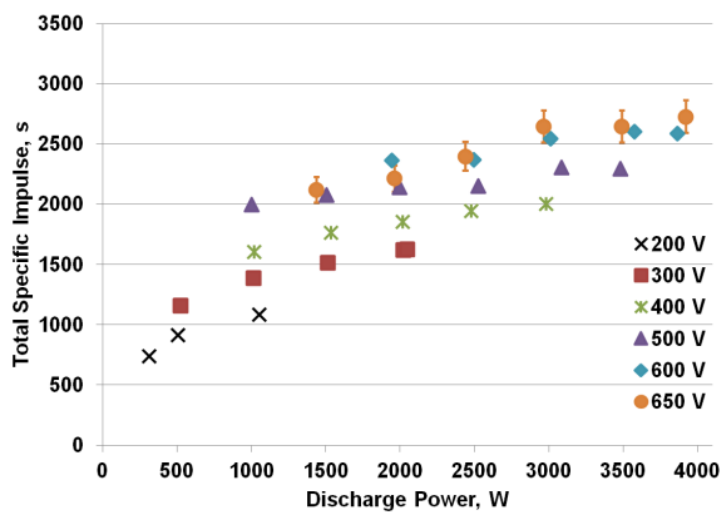

Figure 12. Post-vibration test EDU 2 discharge specific impulse vs. discharge power for discharge voltages between 200 and $650 \mathrm{~V}$.

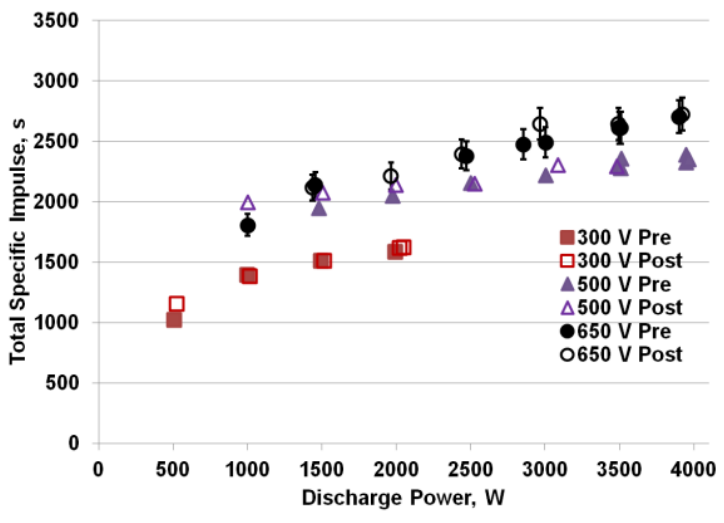

Figure 14. EDU 2 pre-and post-vibration test total specific impulse vs. discharge power for selected discharge voltages. 


\section{B.2 Far-Field Ion Current Density Measurements}

Far-field current density measurements were performed in EDU 2 plume $450 \mathrm{~mm}$ from thruster exit plane. Measurements were mainly made to assess the degree of plume divergence and to determine how plume divergence varies at various operating conditions. A second motivation for performing the measurements was to assess how the thruster plume profile varied due to subjecting EDU 2 to a vibration test. Detailed far-filed ion density measurements are presented by Huang et al. in a companion paper. ${ }^{24}$ Figure 15 presents a representative ion current density profile comparing the pre- and post-vibration test profiles for EDU 2 operation at $2 \mathrm{~kW}$ and $650 \mathrm{~V}$. Study conclusion indicate that the plume divergence angle of the thruster was found to vary from $16^{\circ}$ to $28^{\circ}$ with higher discharge voltage conditions having lower ion beam divergence and that EDU 2 plume underwent no meaningful change due to the thruster being subjected to vibration testing.

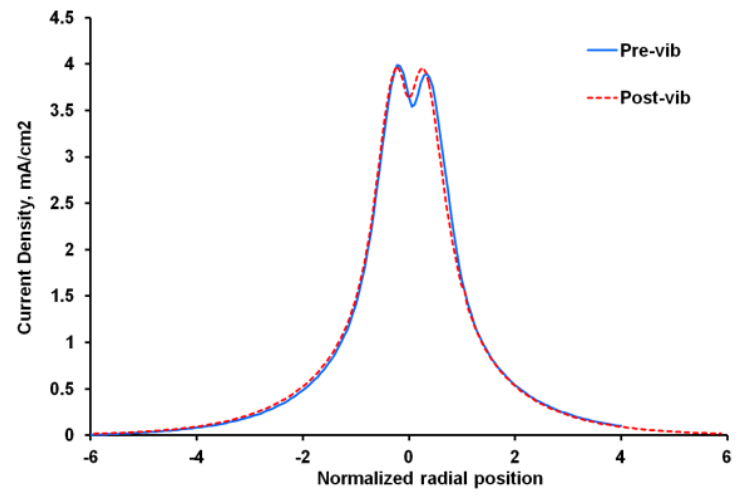

Figure 15. Pre- and post- random vibration test ion current density profiles at $2 \mathrm{~kW}$ and $650 \mathrm{~V}$.

\section{B.3 Thermal Characterization Tests}

Engineering Development Unit 2 was instrumented with 14 type-k thermocouples to measure critical component temperatures. Temperature of the inner electromagnet, anode mount, anode isolator, inner and outer boron nitride discharge channels, backpole, and radiator were monitored and recorded during the thermal characterization tests. Temperature measurements of EDU 2 were made to confirm that the design changes alleviated the elevated temperatures that were measured during EDU 1 testing. Additionally, insight gained from the temperature measurements will result in a better understanding of the power deposition into the thruster's internal components at various power levels. ${ }^{25,26}$ During thruster operation, input discharge power is converted into potential and kinetic power. Potential power is the power consumed in ionizing and exciting the xenon propellant, whereas kinetic power is divided into directed (thrust) and non-directed power. ${ }^{27}$ The non-directed kinetic power is the power portion that contributes to the heating of the various thruster components by the plasma discharge. Non-directed kinetic power has two primary components: heat dissipated into the thruster and radial kinetic power. ${ }^{27}$

Component temperature measurements were performed for steady state thruster operation. Steady state temperature measurements were obtained for thruster operating at $2.5 \mathrm{~kW}\left(\mathrm{~V}_{\mathrm{d}}=500 \mathrm{~V}\right.$ and $\left.\mathrm{I}_{\mathrm{d}}=5 \mathrm{~A}\right), 3.1 \mathrm{~kW}\left(\mathrm{~V}_{\mathrm{d}}=600\right.$ $\mathrm{V}$ and $\left.\mathrm{I}_{\mathrm{d}}=5 \mathrm{~A}\right), 4.2 \mathrm{~kW}\left(\mathrm{~V}_{\mathrm{d}}=500 \mathrm{~V}\right.$ and $\left.\mathrm{I}_{\mathrm{d}}=8.25 \mathrm{~A}\right)$, and $4.2 \mathrm{~kW}\left(\mathrm{~V}_{\mathrm{d}}=650 \mathrm{~V}\right.$ and $\left.\mathrm{I}_{\mathrm{d}}=6.52 \mathrm{~A}\right)$.

In general, the thermal characterization results confirmed that the design changes incorporated in EDU 2 alleviated the elevated inner electromagnet temperatures that were encountered during EDU 1 testing. Peak inner electromagnet temperatures of approximately $480{ }^{\circ} \mathrm{C}$ were measured at $4.2 \mathrm{~kW}$. In addition, measurements of the discharge channel wall temperatures indicate that peak boron nitride discharge channel temperatures of $\sim 600{ }^{\circ} \mathrm{C}$ were recorded at $4.2 \mathrm{~kW}$. Detailed tabulation of the thermal characterization results is beyond the scope of this paper, but details of the results as well as detailed thermal modeling and analysis of the results will be performed and presented at an upcoming Joint Army Navy NASA Air Force Space propulsion Subcommittee conference.

\section{B.4 Vibration Tests}

Vibration testing of the EDU 2 was performed to verify that the thruster design, which includes a discharge channel replacement mechanism, is able to withstand and survive the random vibration test loads that are consistent with Delta-class launch vehicles and typical placement of electric propulsion thruster on spacecraft. ${ }^{28}$ Vibration testing of EDU 2 was performed at Aerojet's vibration test laboratory in Redmond, Washington during the week of May 7, 2012. The EDU 2 thruster that was subjected to the vibration test is the same hardware that underwent hotfire testing in April, 2012. No alterations or modifications were performed on the thruster configuration after the performance test and prior to the vibration test. Three A-frame arms and associated brackets were attached to EDU 2 prior to the vibration test. The A-frame arms were installed to simulate the presence of a thrust vector gimbal, providing vibration transfer characteristics and applied loads more representative of a likely flight application. No functional gimbal was used in this testing because the HiVHAc thruster has not yet been selected for a mission as such, no vectoring requirements exist to date, and the gimbal design is presently beyond the scope of the HiVHAc project. 
The qualification level test specifications are presented in Table 3 and are identical to levels used in qualification testing of the NEXT thruster. ${ }^{21}$ The power spectral density listed in Table 3 results in an overall vibration level of $11.4 \mathrm{G} \mathrm{rms}$, and is performed in each of three orthogonal axes for 3 minute duration per axis.

Table 3. Assembly Qualification Random Vibration Test Acceleration Inputs.

\begin{tabular}{|c|c|c|}
\hline Assembly & Frequency, Hz & Qual., PF Level \\
\hline & $20 \mathrm{~Hz}$ & $0.04 \mathrm{G}^{2} / \mathrm{Hz}$ \\
& $20-50 \mathrm{~Hz}$ & $+3 \mathrm{~dB} /$ Octave \\
Thruster and & $50-600 \mathrm{~Hz}$ & $0.1 \mathrm{G}^{2} / \mathrm{Hz}$ \\
Gimbal & $600-2000 \mathrm{~Hz}$ & $-6 \mathrm{~dB} /$ octave \\
& $2000 \mathrm{~Hz}$ & $0.03 \mathrm{G}^{2} / \mathrm{Hz}$ \\
& Overall & $11.4 \mathrm{Grms}$ \\
\hline
\end{tabular}

Vibration testing in the two radial directions ( $\mathrm{X}$ and $\mathrm{Z}$ axes) were performed first, and then testing was performed along the thrust axis ( $\mathrm{Y}$ axis). Figure 16 shows a photograph of EDU 2 at Aerojet's vibration test laboratory. Prior to performing the test, a fixture survey was carried out to verify instrumentation and confirm that abort-limits were in effect. The first axis tested was the $\mathrm{X}$-axis. For each axis, the first test performed was a low level sine sweep over the frequency range of 5 to $2,000 \mathrm{~Hz}$. A uniform vibration level of $0.5 \mathrm{~g}$ was maintained, with a frequency sweep rate of two octaves per minute. This was followed by random vibration at reduced level for about one minute, and then full-level testing for $180 \mathrm{sec}$. Upon completion of the 3 minute random vibration test the low level sine sweep was repeated. An identical sequence was carried out for the $\mathrm{Z}$ axis. Upon completion of the radial axes testing ( $\mathrm{X}$ and $\mathrm{Z}$ ), the shaker table was re-configured for longitudinal (thrust axis-Y) testing, shown in Figure 16c. For all three axes tested, the thruster hardware and fixture plate were instrumented with fifteen accelerometers. The accelerometers were placed on the fixture plate, the A-frame bracket, the cathode keeper plate, the cathode bracket, the inner and outer boron nitride discharge channels, and the radiator.

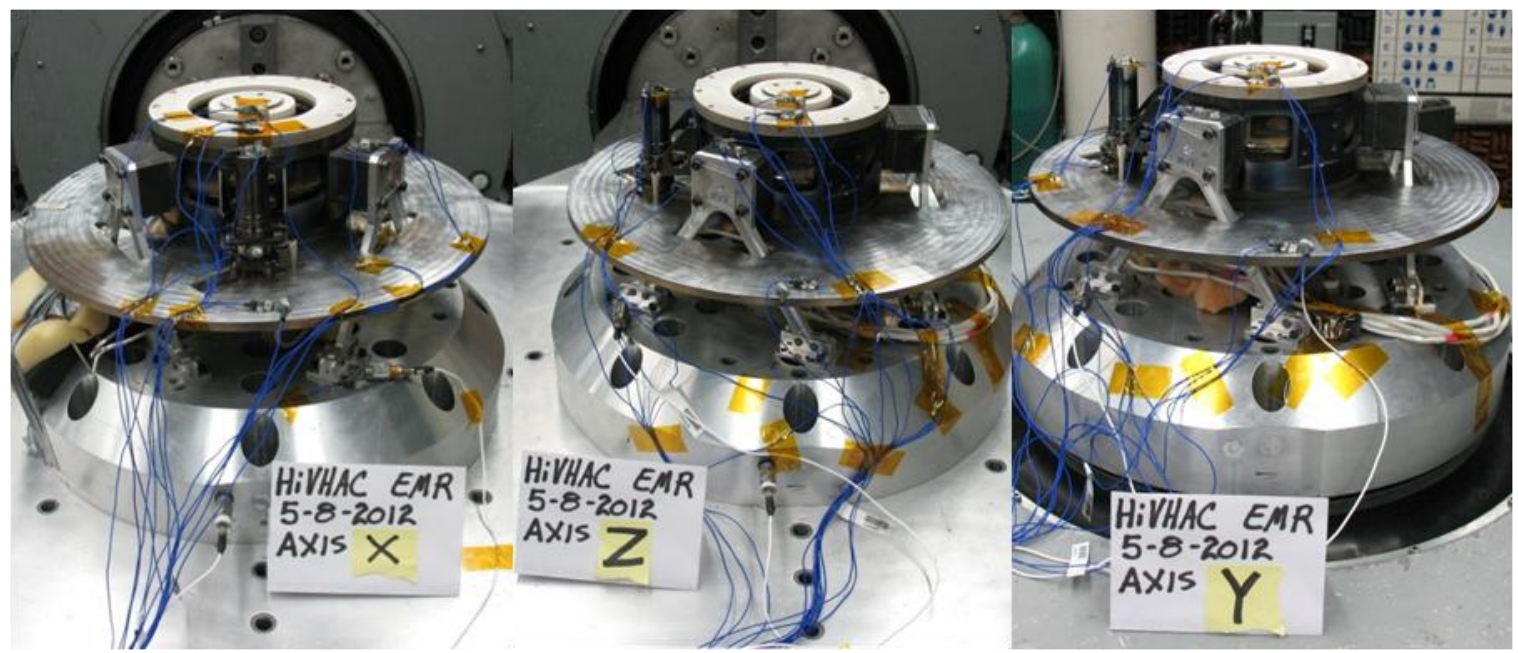

Figure 16. Photograph of EDU 2 setup for $\mathrm{X}(\mathrm{a}), \mathrm{Z}(\mathrm{b})$, and $\mathrm{Y}(\mathrm{c})$ axes vibration testing at Aerojet's vibration test laboratory.

For this paper a brief discussion of the vibration test results will be presented for the $\mathrm{X}$ axis vibration test results. Representative signals are shown for the inner boron nitride discharge channel accelerometer (channel 10). Figure 17a shows the response signal for the $\mathrm{X}$-axis low-level sine sweep, before the random vibration test. At $20 \mathrm{~Hz}$, the vibration amplitude is shown to be $0.5 \mathrm{~g}$, which increases only slightly as frequency increases though $70 \mathrm{~Hz}$. First mode resonance occurs at $168.9 \mathrm{~Hz}$, showing $8.7 \mathrm{~g}$ and an amplification factor of about 17. The response amplitude then decreases steadily as frequency passes $300 \mathrm{~Hz}$. A small secondary peak occurs at a frequency of about $340 \mathrm{~Hz}$, followed by more complex responses up through $2000 \mathrm{~Hz}$. Figure 18 shows response during the full-level random vibration test cycle. The power spectral density of the response accelerometer is consistent with force input levels from $20 \mathrm{~Hz}$ through $50 \mathrm{~Hz}$. Under random vibration, first mode resonance occurs at $155 \mathrm{~Hz}$, as compared with 168.9 $\mathrm{Hz}$ resulting from the sine sweep. Response decreased through about $300 \mathrm{~Hz}$, but a small secondary peak is seen at $340 \mathrm{~Hz}$ analogous to sine sweep results. Larger responses are seen between 400 and $900 \mathrm{~Hz}$, but there is little response beyond $1000 \mathrm{~Hz}$. The post random vibration sine sweep is shown in Figure 17b. As before, the vibration 
amplitude remains $0.5 \mathrm{~g}$ up through about $70 \mathrm{~Hz}$. First mode resonance occurs at $170.6 \mathrm{~Hz}$, which is very close to the pre-random vibration resonance. Peak amplitude is $5.5 \mathrm{~g}$, which indicates more damping compared to the prerandom vibration response. It is possible that radial clearance between movable parts may not be as tight in the post-test hardware when compared to the pre-test state. The $\mathrm{X}$ axis was tested first, so that pre-test sine sweeps occurred on a relatively fresh assembly. As with earlier results, a small secondary peak is seen at about $340 \mathrm{~Hz}$.

Vibration test results and thruster inspection after test completion indicated that the thruster withstood and survived qualification level loads specified in Table 3. Inspection of thruster hardware after each axis sweep confirmed that all visible thruster components were still in their original assembled configuration.
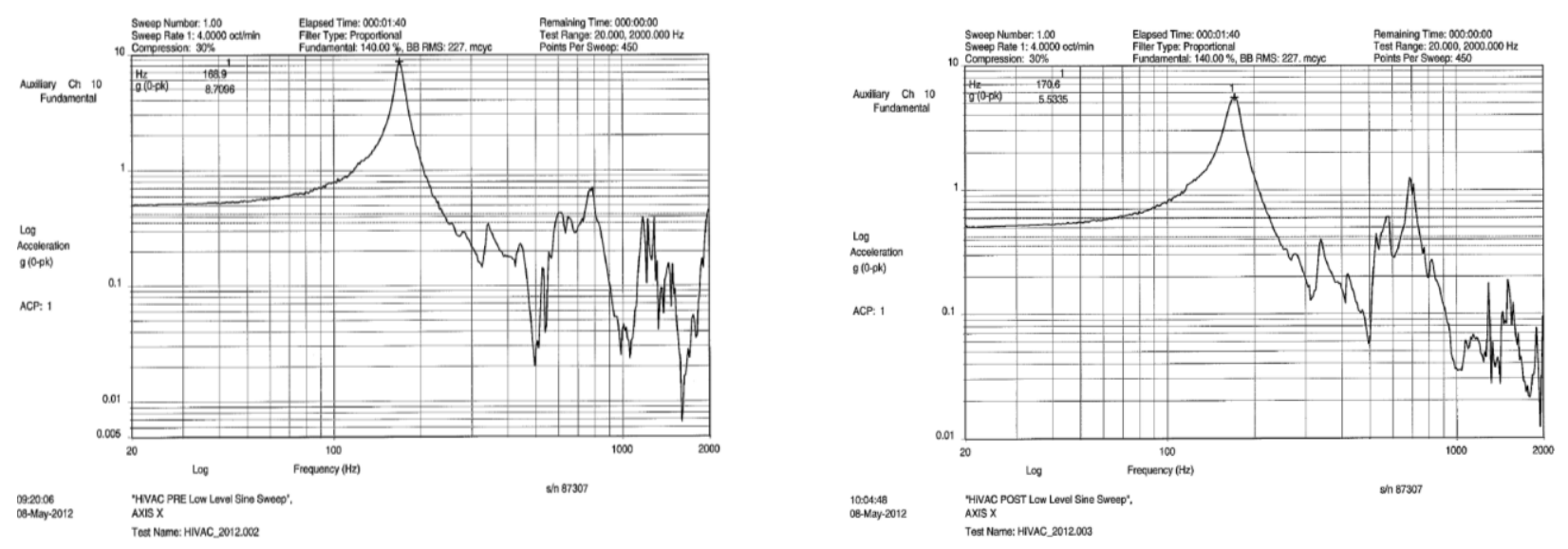

Figure 17. Pre-(left) and post- (right) vibration sine sweep comparison in the $\mathrm{X}$-axis.

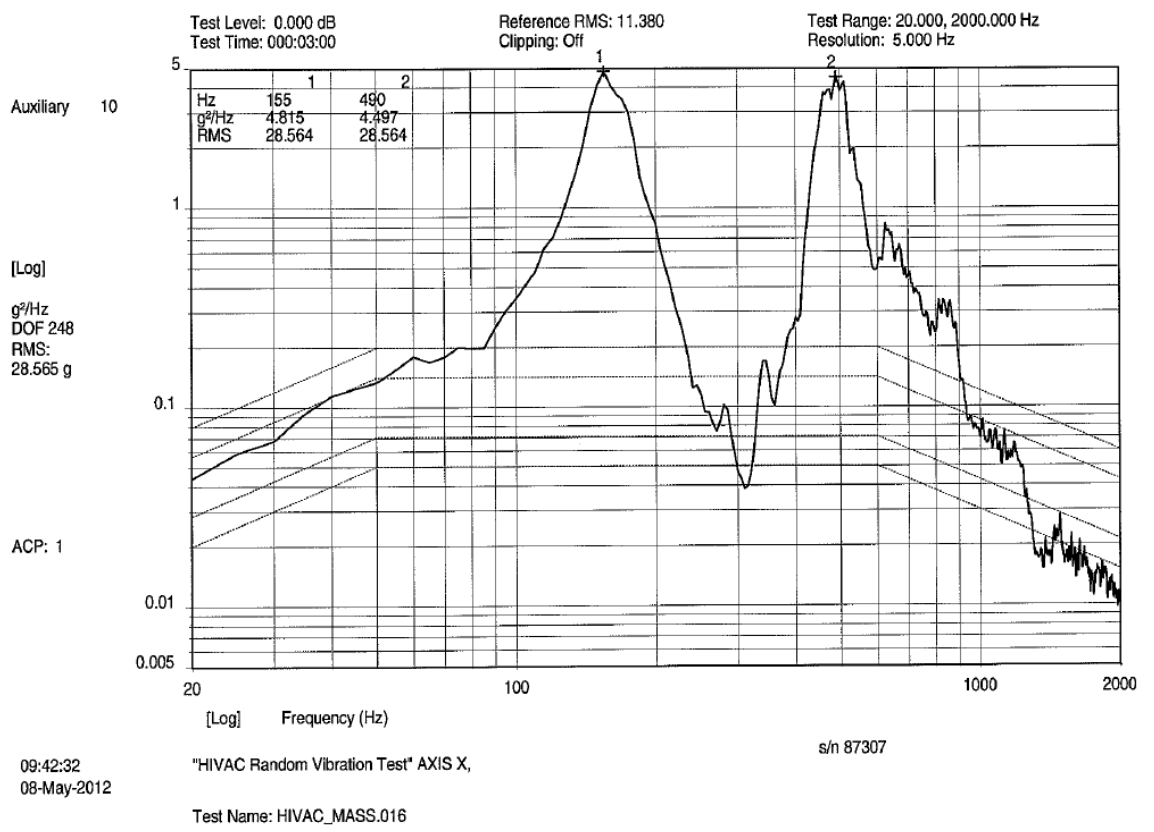

Figure 18. Accelerometer response during full-level random vibration testing in the $\mathbf{X}$-axis. 


\section{Power Processing Unit Options}

The HiVHAc PPU functional requirements are that it can operate over a 0.3 to $3.9 \mathrm{~kW}$ throttling range, and can supply output voltages between 200 and $700 \mathrm{~V}$ for input voltages between 80 and $160 \mathrm{~V}$. Environmental requirements were derived from the NEXT thruster requirements documents. ${ }^{21}$

NASA is looking at various options to perform some critical design and testing of PPU converter topologies dependent on funding availability. The near term plan is to leverage converter/PPU development by other projects. One option is to implement new discharge modules that are being developed by Aerojet. ${ }^{29}$ Another option is to leverage Hall thruster PPU developments within NASA's small business innovative research (SBIR) program. Three SBIR projects are developing wide range discharge modules for integration with Hall thrusters. The SBIR projects are the Busek Company Inc. "High Efficiency Hall Thruster Power Converter", Colorado Power Electronics (CPE) Inc. "Low Cost High Performance Hall Thruster Support System", and Arkansas Power Electronics International Inc. "Silicon Carbide PPU For Hall Effect Thrusters".

The highest maturity SBIR program produced PPU is a CPE designed and built PPU shown in Figures 19 and 20. The PPU contains two high voltage discharge modules, cathode heater and keeper power supplies, and two electromagnet power supplies. The $3.9 \mathrm{~kW}$ PPU can operate at input voltages between 80 and $160 \mathrm{~V}$ and is capable of output voltages between 200 and $725 \mathrm{~V} .{ }^{30}$ The unit's discharge modules use an innovative three-phase resonant topology capable of efficiently delivering full power over the wide input and output voltage ranges. Extensive atmospheric and vacuum testing of the CPE discharge modules was performed at NASA GRC and was reported in Reference 31. Extensive testing of CPE PPU has been performed over the past year. The CPE PPU was used to power EDU 2 during the various performance tests that were reported in this paper. In addition, CPE's PPU has undergone a 1,500 hour vacuum burn in test at $3.5 \mathrm{~kW}$ into a resistive load. During the 1,500 hour test, temperature readings of twenty critical PPU components were monitored and recorded at various operating discharge current and voltage settings and at different base plate operating temperatures. Detailed reporting and discussion of the CPE PPU tests will be presented at an upcoming conference since it is beyond the scope of this paper.

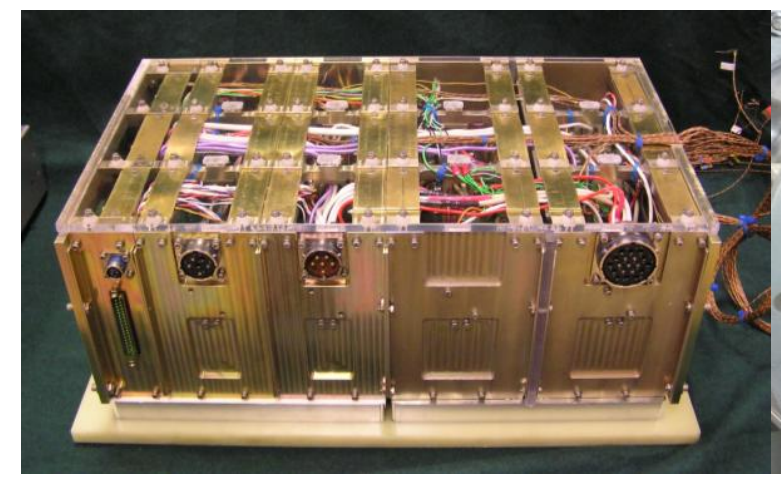

Figure 19. Photograph of the Colorado Power Electronics brassboard PPU.

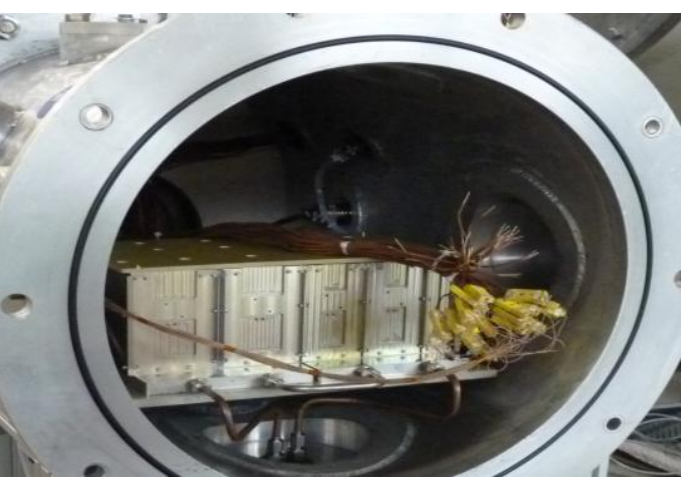

Figure 20. Photograph of the Colorado Power Electronics brassboard PPU inside VF70.

\section{Xenon Feed System}

In 2008, the HiVHAc thruster was hot-fire tested with VACCO's first generation XFS. ${ }^{32}$ As a result of the successful testing of the HiVHAC thruster with the VACCO XFS, NASA GRC and AFRL acquired a flight-like VACCO advanced XFS for integration with the HiVHAc propulsion system and other EP devices of interest to the Air Force. The HiVHAc project plan is to use the VACCO ChEMS XFCM. The XFCM is a low-cost, light-weight, low-power consumption XFS, which represents a dramatic improvement over the NSTAR flight feed system and also an additional $70 \%$ reduction in mass, 50\% reduction in footprint, and 50\% reduction in cost over the baseline NEXT XFS. The XFCM is designed as a two channel electronic flow controller with a series redundancy to protect against leakage. It includes integral pressure and temperature sensors. The unit is designed to withstand and comply with the vibration, thermal, and shock loads environments for NASA missions. 
The XFCM unit was delivered to NASA GRC in June of 2012. Compliance with the flow accuracy, power consumption, vibration environment, shock environment, thermal environment, and minimum and maximum inlet pressure operation was demonstrated by test. Figure 21 presents a layout and picture photograph of the XFCM. Table 4 lists some of the XFCM specifications.

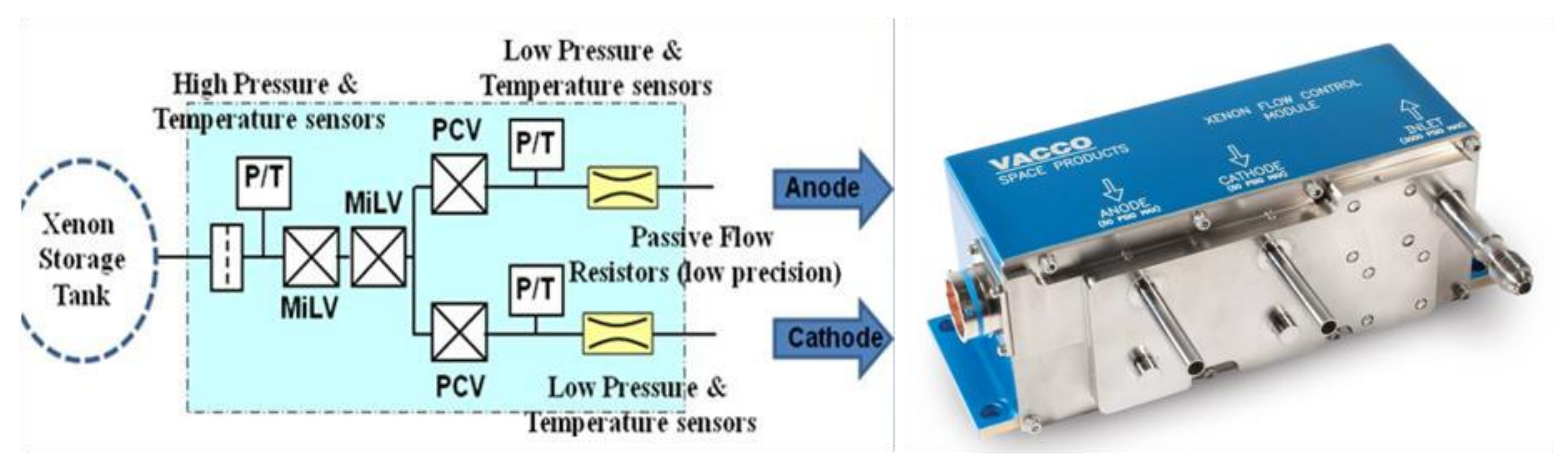

Figure 21. VACCO XFCM layout and photograph.

Table 4. VACCO XFCM Specifications

\begin{tabular}{|l|l|}
\hline Inlet Pressure Range & 10 to $3000 \mathrm{psia}$ \\
\hline Anode Flow Range & 0 to $80 \mathrm{sccm}$ Xenon \\
\hline Cathode Flow Range & 0 to $80 \mathrm{sccm}$ Xenon \\
\hline Flow Accuracy & $\pm 3 \%$ of Set Value (closed loop) \\
\hline Internal Leakage & $10 \times 10^{-3} \mathrm{scch}$ GHe \\
\hline External Leakage & $1.0 \times 10^{-6} \mathrm{sccs}$ \\
\hline Lifetime & 10 years, 7,300 cycles, $100 \%$ margin \\
\hline Mass & $<1.25 \mathrm{~kg}$ \\
\hline Power Consumption & $<1 \mathrm{~W}$ steady state \\
\hline Size $(\mathrm{W} \times \mathrm{H} \times \mathrm{D})$ & $19.5 \mathrm{~cm} \times 7 \mathrm{~cm} \times 7.5 \mathrm{~cm}$ \\
\hline
\end{tabular}

\section{High Voltage Hall Accelerator Engineering Development Unit 2 Test Roadmap}

The EDU 2 test roadmap is shown in Figure 22. The roadmap signifies the path EDU 2 will pursue to demonstrate its flight worthiness and its service life capability. The test readiness boxes shown in Figure 22 with a green fill/background indicate completed tasks and tests. The next steps in EDU 2 test plan include performing a thermal vacuum test. Upon successful completion of the thermal vacuum test at JPL, additional functional and abbreviated performance testing will be performed at NASA GRC followed by detailed near- and far-field plume mappings. After completing EDU 2 plume characterization tests, a 1,000 to 2,000 hours wear test will be performed. The diagnostics that will be employed during that test will include a pneumatically controlled quartz-crystal microbalance (QCM) six sensor head, pinhole cameras, quartz witness plates, Faraday ion flux probes, retarding potential analyzers (RPA), E $\times \mathrm{B}$ probe, electrostatic probes, and an in-vacuum laser profilometer to monitor the discharge channel erosion. After successfully completing the short duration test, a long duration test (LDT) will be initiated. The LDT will be performed at NASA GRC VF12, and will utilize and incorporate all the diagnostics that were used during the previous series of tests. 


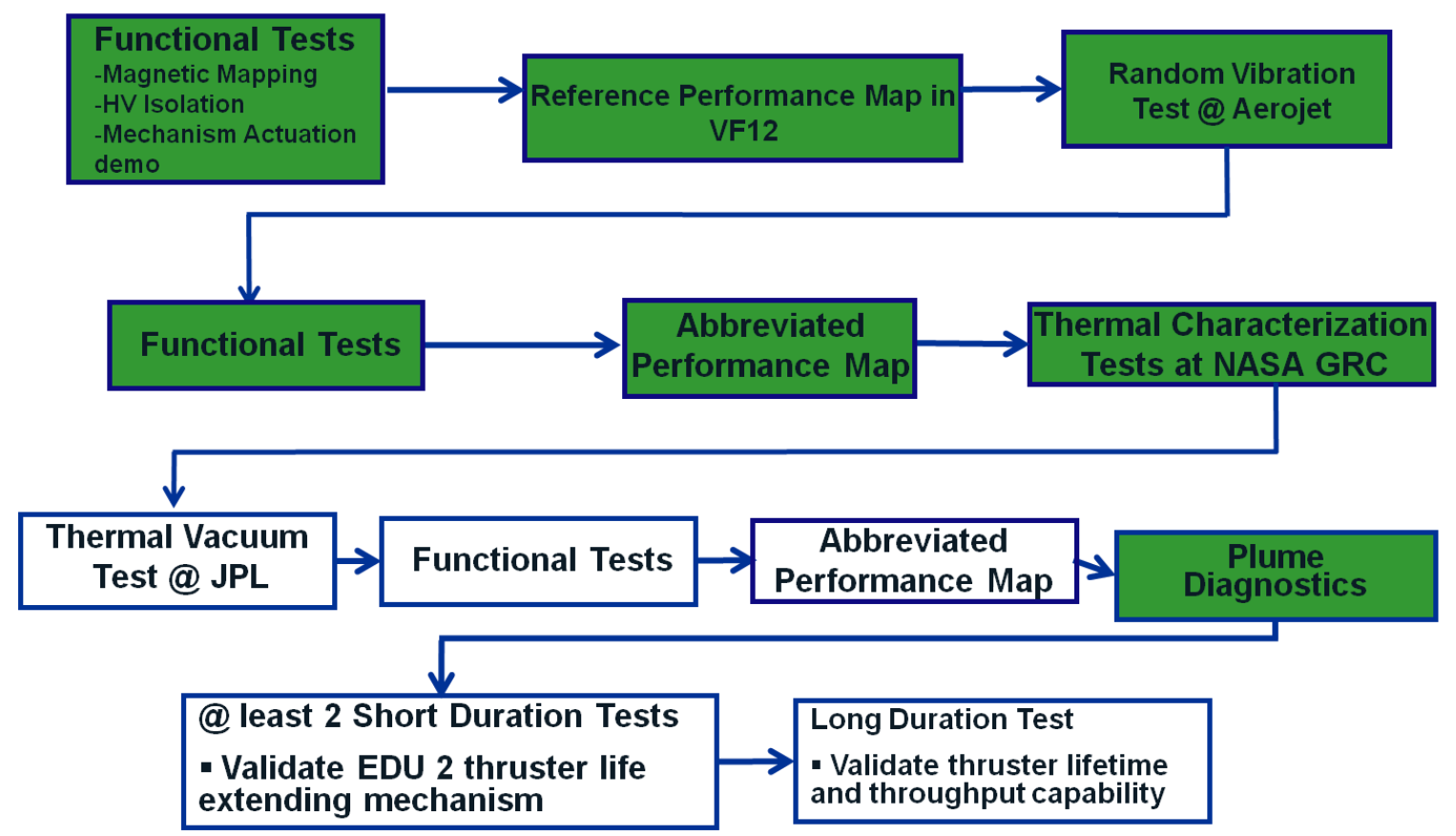

Figure 22. HiVHAc EDU 2 Test Roadmap.

\section{Summary}

Performance testing of EDU 2 was completed over power levels between 0.3 and $3.9 \mathrm{~kW}$. Testing of EDU 2 indicated that the thruster operation was nominal across the entire operating power range. At $3.9 \mathrm{~kW}$ and a discharge voltage of $650 \mathrm{~V}$ the thruster achieved a total thrust efficiency of 58\% and a total specific impulse of 2,700 sec.

Thermal characterization test results confirmed that the design changes made to EDU 1 and incorporated in EDU 2 alleviated the elevated inner electromagnet temperatures that were encountered during EDU 1 testing. Temperature measurements of the various instrumented thruster components indicated that peak measured component temperatures are below the prescribed thruster materials' maximum operating temperatures.

Full-level random vibration testing of EDU 2 was performed in three axes: $\mathrm{X}$ and $\mathrm{Z}$ axes (lateral) and the $\mathrm{Y}$ axis. Inspection of the thruster hardware after each test cycle confirmed that the thruster withstood and survived the fulllevel applied loads. No changes to the assembled thruster configuration were observed. Post-vibration test performance evaluation confirmed that the thruster performance was not altered due to being subject to a full-level three axes random vibration test.

Finally, development of the HiVHAc power processing unit and xenon feed system is ongoing. A brassboard power processing unit developed by Colorado Power Electronics, Inc. has undergone extensive functional testing with EDU 2 and a resistive load. A 1,500 hour vacuum burn-in test was performed at $3.5 \mathrm{~kW}$, the test included monitoring and recording of the temperature of twenty components. A VACCO advanced xenon feed control module unit that has undergone qualification testing was recently delivered to NASA GRC, the unit will be incorporated in future EDU 2 tests.

\section{Acknowledgments}

The work described in this paper is funded by NASA's Science Mission Directorate In-Space Propulsion Technology office. The authors would also like to thank Kevin Blake, Mike Pastel, Richard Pollack, Kevin McCormick, George Readus, and George Jacynycz for their relentless support of the HiVHAc project.

\section{References}

${ }^{1}$ Committee on the Planetary Science Decadal Survey Space Studies Board, "Vision and Voyages for Planetary Science in the Decade 2013-2022." 
${ }^{2}$ Sovey, J. S., Rawlin, V. K., and Patterson, M. J., "Ion Propulsion Development Projects in U.S.: Space Electric Rocket Test to Deep Space 1," Journal of Propulsion and Power, Vol. 17, No. 3, May-June 2001, pp. 517-526.

${ }^{3}$ Russel, C. T., et al., "Dawn: A Journey to the Beginning of the Solar System," DLR International Conference on Asteroids, Comets, and Meteors, July-August 2002.

${ }^{4}$ NASA's Science Mission Directorate Science Plan for 2007-2016.

${ }^{5}$ Dankanich, J. W., "Electric Propulsion for Small Body Missions", AIAA Paper 2010-6614, August 2010.

${ }^{6}$ Dankanich, J.W., Drexler, J. A., and Oleson, S. R., "Electric Propulsion Mission Viability with the DiscoveryClass Cost Cap," AIAA Paper 2010-6776, August 2010.

7 Pencil, E., et. al, “Overview of NASA's Electric Propulsion Development Activities for Robotic Science Missions", IEPC Paper 2011-161, September 2011.

8 Benson, S., Patterson, M, and Snyder, S., "NEXT Ion Propulsion System Progress Towards Technology Readiness," AIAA Paper 2008-5285, July 2008.

${ }^{9}$ Kamhawi, H., et al., "Overview of the Development of a Low Cost High Voltage Hall Accelerator Propulsion System for NASA Science Missions," AIAA Paper 2011-5520, July, 2011.

${ }^{10}$ Oh, D. "Evaluation of Solar Electric Propulsion Technologies for Discovery Class Missions," AIAA Paper 20054270, July 2005.

${ }^{11}$ Witzberger, K. E., et al., "NASA's 2004 In-Space Propulsion Re-focus Studies for New Frontiers Class Missions," AIAA Paper 2005-4271, July 2005.

${ }^{12}$ Jacobson, D., et al. "NASA's 2004 Hall Thruster Program,” AIAA Paper 2004-3600, July 2004.

${ }^{13}$ Manzella, D., Oh, D., and Aadland, R., "Hall Thruster Technology for NASA Science Missions," AIAA Paper 2005-3675, Tucson, Arizona, 2005.

${ }^{14}$ Dankanich, J., Kamhawi, H., and Mathers, A., "HiVHAc Maximum Operating Power Range," IEPC Paper 2009213, September 2009.

${ }^{15}$ De Grys, Kristi, et al., "4.5 kW Hall Thruster System Qualification Status,” AIAA Paper 2005-3682, July 2005.

${ }^{16}$ Peterson, P., Kamhawi, H., Manzella, D., and Jacobson, D., "Hall Thruster Technology for NASA Science Missions: HiVHAc Status Update," AIAA Paper 2007-5236, July 2007.

${ }^{17}$ Kamhawi, H., "Various Hollow Cathode Configurations Testing for the High Voltage Hall Accelerator," AIAA Paper 2007-5172, July 2007.

${ }^{18}$ Kamhawi, H., Manzella, D., and Peterson, P., "High Voltage Hall Accelerator Wear Test Update," presented at JANNAF, Orlando, Florida, December 2008.

${ }^{19}$ Mankins, J., “Technology Readiness Levels," http://www.hq.nasa.gov/office/codeq/trl/trl.pdf.

${ }^{20}$ Mathers, A., Aadland, R., Manzella, D., and Kamhawi., H., "Development Status of The HiVHAc Thruster," AIAA Paper 2008-4524, July 2008.

21 "NEXT Technical Requirements and Validation Document," Internal memorandum, GRC-NEXT-200, November 2007.

${ }^{22}$ Kamhawi, H., et al., "Overview of the Development of a Low Cost High Voltage Hall Accelerator Propulsion System for NASA Science Missions," AIAA Paper 2011-5520, July 2011.

${ }^{23}$ Haag, T., Osborn, M., "RHETT/EPDM Performance Characterization", NASA/TM 1998-20622.

${ }^{24}$ Huang, W., Kamhawi, H., and Shastry, R., "Far-field Ion Current Density Measurements before and after the NASA HiVHAc EDU2 Vibration Test," AIAA Paper 2012-4195, July 2012.

${ }^{25}$ Kamhawi, H., Manzella, D., Mathers, A., and Aadland, R., "In-Space Propulsion High Voltage Hall Accelerator Thruster Development Project Overview," SPS-III-10, presented at JANNAF, December 2008.

${ }^{26}$ Mathers, A., Aadland, R., Manzella, D., and Kamhawi., H., "Development Status of The HiVHAC Thruster," AIAA Paper 2008-4524, July 2008.

${ }^{27}$ De Grys, K., Rayburn, C., and Hass, J., "Study of Power Deposition In the BPT-4000 Hall Thruster," AIAA Paper 2003-5277, July 2003.

${ }^{28}$ Snyder, J. S., et al., "Environmental Testing of the NEXT PM1Thruster," AIAA Paper 2007-5275, July, 2007.

${ }^{29}$ Sultan, A., et al., "Development of a Modular Hall Thruster Power Converter," AIAA Paper 2011-5997, July 2011.

${ }^{30}$ Hesterman, B., “Wide Range Multi-Phase Resonant Converters,” JANNAF-1435, May 2010.

${ }^{31}$ Pinero, L. R., Kamhawi, H., and Drummond, G., "Integration Testing of a Modular Discharge Supply for NASA's High Voltage Hall Accelerator Thruster," IEPC Paper 2009-275, September 2009.

${ }^{32}$ Dankanich, J., et. al., "Advanced Xenon Feed System Development and Hot Fire," AIAA Paper 2009-4910, August 2009. 